\title{
Two-Phase Spiral CT
}

National Cancer Institute

\section{Source}

National Cancer Institute. Two-Phase Spiral CT. NCI Thesaurus. Code C19906.

A type of computed tomography whereby images of two separate phases of contrast medium perfusion are taken. 